\title{
Gear Fault Identification by using Vibration Analysis
}

\author{
Ajanalkar Sagar Shivputra ${ }^{{ }^{*}}$ and Ganesh D. Shrigandhi ${ }^{\ddagger}$ \\ †Department of Mechanical Engineering, Student at NBNSCOE, Solapur University, Solapur, India \\ ‡Department of Mechanical Engineering, Faculty at MITCOE, Savitribai Phule Pune University, Pune, India
}

Accepted 02 March 2016, Available online 15 March 2016, Special Issue-4 (March 2016)

\begin{abstract}
Nowadays it is becoming more essential and reliable to predict the performance of gear box without dissembling the gear box. It is possible to predict the fault and fault conditions in case of any rotary machinery by using vibration analysis with the help of FFT analyzer and its accessories. In this paper, the similar kind of experimental setup is prepared and the vibration analysis is carried out at different speeds to analyze the behavior of time waveform and FFT spectrum for three different fault conditions. The gear pair of Bajaj Pulsar gear box is taken and the faults are created on pinion and the vibration behavior is observed. The three fault conditions are single tooth damaged pinion, double teeth damaged pinion and worn pinion. Also some of the numerical techniques like RMS value and variance are used for comparing the behavior of faulty pinion with respect to healthy pinion.
\end{abstract}

\section{Keywords: Vibration Analysis, Fault Identification, Gear Fault.}

\section{Introduction}

Gear is the most important part used in any power transmission system. Gears are generally used to transfer power from one shaft to another shaft. A gear box consisting of many number of gears inside it to transmit power coming from engine to the wheels. Various types of gears are used such as spur, helical, bevel and epicycle gears (V. B. Bhandari, 2010).

As the gears are power transmitting elements, certain faults are getting created in the gears. The faults like tooth damage, wear, pitting, chipping are getting created in the gears due to various reasons like excess loading, large friction and fatigue loading, etc. Also some of the faults like backlash, eccentricity, run out and alignment error are caused during assembling and manufacturing of gear. The faults will create the noise and vibrations during its working condition. These parameters can be used to identify the fault condition as each and every fault condition creates a different vibration spectrum. So it becomes necessary to identify the fault conditions in gear box by using proper vibration analysis technique (A. Jaiswal, et al, 2013).

In this study, an experimental setup is prepared for testing fault conditions in a single gear pair of Bajaj Pulsar gear box. The faults like single tooth damage, double teeth damage and wear are created on the small gear (pinion) same as that of getting created in actual case. These gears are meshed and the vibration analysis is carried out at different speeds. The vibration analysis is carried out by using a FFT analyzer and its accessories (G. Diwakar, et al, 2012).

The results are obtained and are compared with the results obtained for healthy gear pair. The results obtained are compared by using time waveform, FFT power spectrum and computational techniques.

\section{Objectives}

The main objectives of this experimentation are as follows:

a. To observe and study the change in vibration signature for faulty gear pair.

b. To detect and asses the severity of faults in the gear pair.

c. To identify diagnostic capability of vibration analysis.

\section{Methodology for fault identification}

The problem and methodology can be easily understood by using the figure 1 .

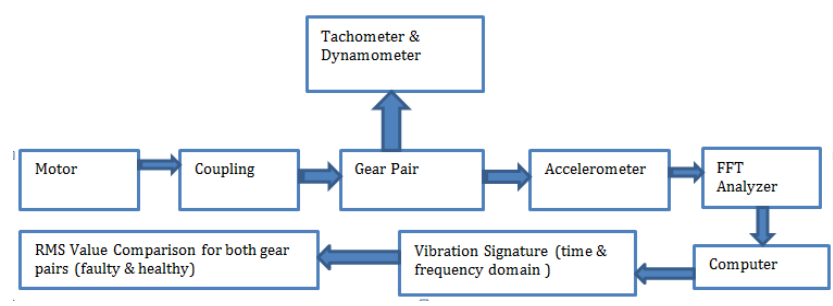




\subsection{Problem definition}

The various types of faults are created on the pinion of Bajaj Pulsar gear box. The faults created are single tooth damage, double teeth damage and wear as shown in figure 2. After creating the faults the pinion and gear are meshed in experimental setup and the vibration parameter (acceleration) is measured at the bearing by using accelerometer. The vibration data is collected by FFT analyzer in a computer system. The data is further analyzed by using the software DEWEsoft X1.

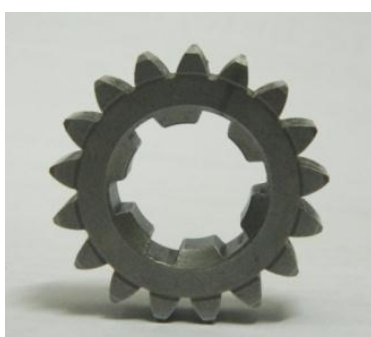

(a) Healthy Pinion

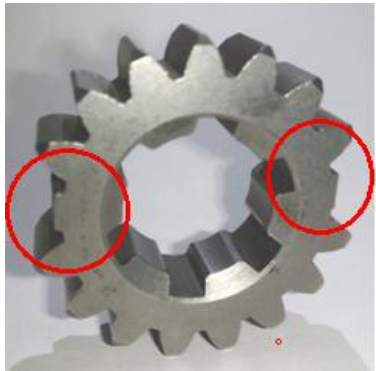

(c) Double teeth damage

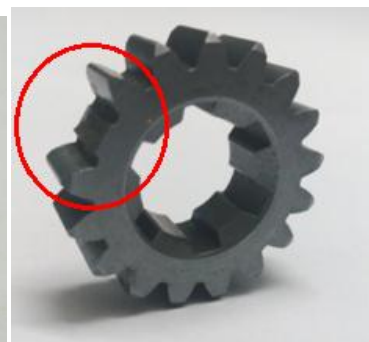

(b) Single Tooth Damage

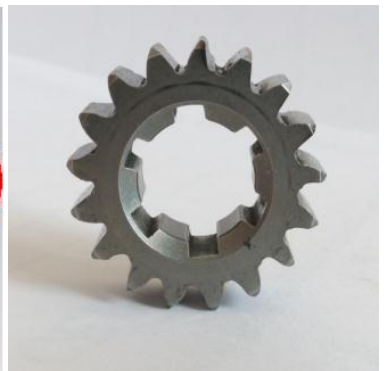

(d) Worn Pinion
Fig. 2 Faults created on pinion

Also the dimensions of a selected gear pair are given in table 1 (V. B. Bhandari, 2010)

Table 1 Specifications of pinion

\begin{tabular}{|c|c|c|c|c|}
\hline Pinion & $\begin{array}{c}\text { OD } \\
\text { in mm }\end{array}$ & Number of teeth & $\begin{array}{c}\text { PCD in } \\
\mathrm{mm}\end{array}$ & $\begin{array}{c}\text { Modul } \\
\mathrm{e}\end{array}$ \\
\hline $\begin{array}{c}\text { Healthy } \\
\text { pinion }\end{array}$ & 35.60 & 17 & 31.85 & 1.87 \\
\hline $\begin{array}{c}\text { Wear in } \\
\text { pinion }\end{array}$ & 35.62 & 17 & 31.85 & 1.87 \\
\hline $\begin{array}{c}\text { Single Teeth } \\
\text { damaged } \\
\text { pinion }\end{array}$ & 35.66 & $\begin{array}{c}16 \\
\text { (after breaking a } \\
\text { tooth) }\end{array}$ & 31.86 & 1.87 \\
\hline $\begin{array}{c}\text { Double teeth } \\
\text { damaged } \\
\text { pinion }\end{array}$ & 35.6 & $\begin{array}{c}15 \\
\text { (after breaking } \\
\text { two teeth) }\end{array}$ & 31.85 & 1.87 \\
\hline
\end{tabular}

\subsection{Methodology}

The methodology used for fault identification and for observing the behavior of various faults is as given:

1. Conducting experimental vibration analysis for healthy gear pair and faulty gear pair by using accelerometer and FFT analyzer.
2. Comparing the vibration analysis results by using the RMS value and variance of vibration parameters for all the gear pairs (Shawki, et al, 2012).

3. Observing and comparing the frequency domain and time domain vibration signatures.

\section{Experimentation}

The experimental setup is prepared to conduct a vibration analysis of healthy and faulty gear pair as shown in figure 3 . The experimental setup consisting of guide frame and base frame on which the gear pair, electric motor and the rope dynamometer are mounted. The motor shaft is connected to the pinion shaft via coupling to transfer the rotary motion. Also the dimmer stat is used to achieve variable speed of pinion. The dynamometer is used to apply loading conditions to observe the vibration behavior of the system during load (A. Jaiswal, et al, 2013).

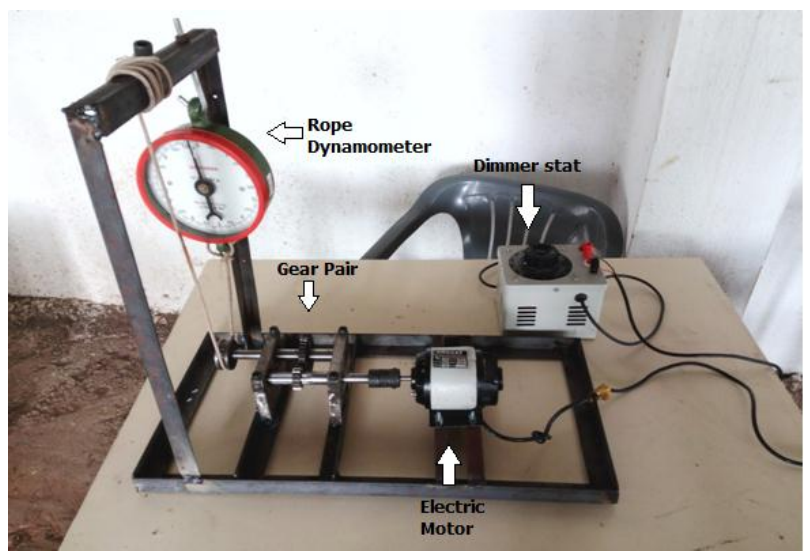

Fig. 3 Experimental Setup

Also, it is necessary to use FFT analyzer and compatible software installed computer to record and analyze the vibration spectrum. The FFT analyzer used for this experimentation is DEWE $43 \mathrm{~A}$. Specifications of FFT analyzer used are - Manufacturer: DEWEsoft, Input Power supply: 9-36 V DC, channel: 8 analog inputs, 8 super counters, Sampling Rate: $200 \mathrm{kS} / \mathrm{s}$, connections interface: USB.

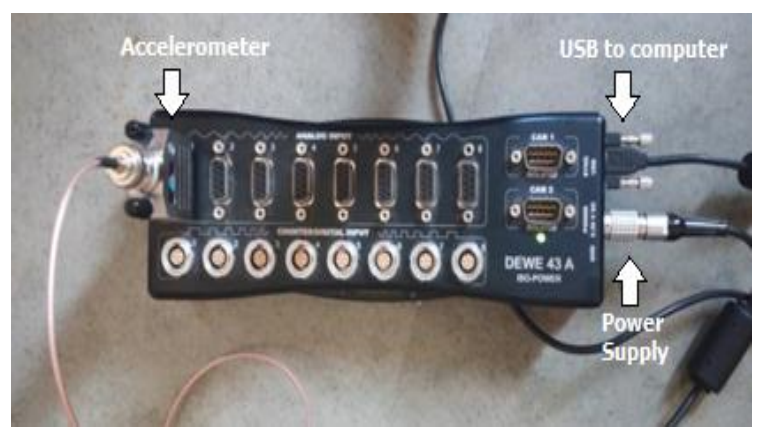

Fig. 4 FFT Analyzer (DEWE 43 A)

As the vibration behavior of healthy and faulty pinion has to be observed, the accelerometer is placed on the 
guiding frame exactly above the bearing of shaft on which the pinion is mounted. The location of accelerometer is shown in the figure 5.

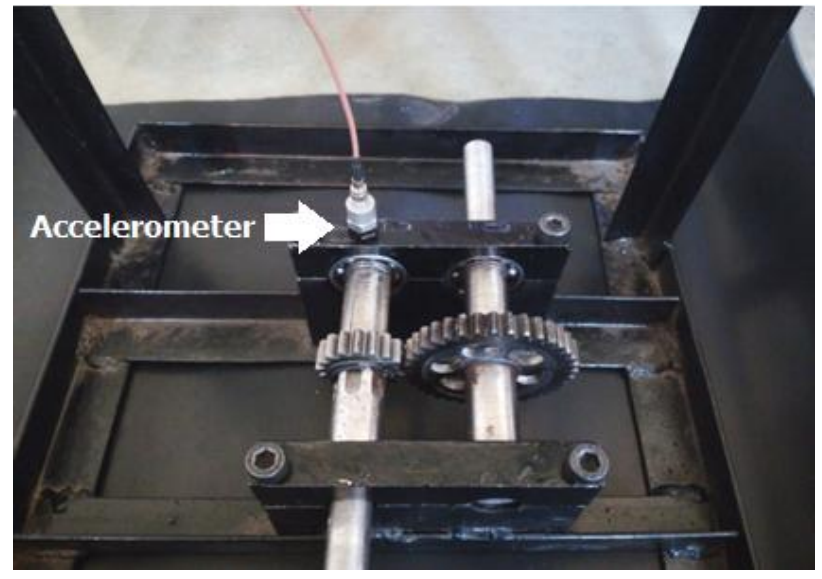

Fig. 5 Location of accelerometer

Selection of location of accelerometer is also one of the most important criteria for successful prediction of fault. In this case, as the provision is made to replace healthy pinion by faulty pinion and as to identify the behavior for different faults created on pinion, the accelerometer is placed on the bearing of shaft on which the pinion is assembled (C. Sujatha, 2010).

A wide range of accelerometers are available but proper is to be selected for proper vibration data recording. The specifications of the accelerometer selected are - Number of axis: 1, sensitivity: $100 \mathrm{mV} / \mathrm{g}$, frequency range: 3 to $10000 \mathrm{~Hz}$, weight: $44 \mathrm{gm}$.

After successful preparation of whole setup, the experimentation was started. The vibration data in the form of time domain for small period of time is collected at $300 \mathrm{rpm}, 600 \mathrm{rpm}, 900 \mathrm{rpm}$ and $1200 \mathrm{rpm}$ by using the software for healthy pinion under loaded and unloaded condition. After collecting the data for healthy pinion, the healthy pinion is replaced by faulty pinion one by one and the time domain data is collected at same conditions.

The collected data is reused for further analysis by using the software DEWEsoft X1. It is provided with different types of functions like FFT spectrum, Filters, various mathematical functions. Amongst these all, in this study the FFT power spectrum and mathematical functions like RMS value and variance are used for fault identification and for observing the vibration behavior.

\section{Results \& Discussions}

The results obtained are divided into following steps according the fault conditions:

\subsection{Single Tooth Damage}

One of the time waveforms for single tooth fault is given in the graph 1 .

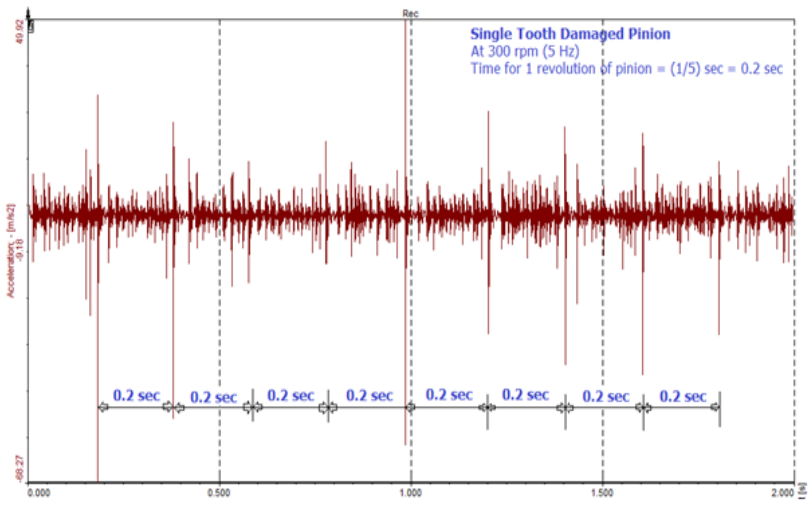

Graph 1 Time Waveform for Single Tooth Damaged Pinion at $300 \mathrm{rpm}$

In this graph, it can be observed that the waveform is plotted by plotting the curve of acceleration on vertical axis and time on horizontal axis.

As the single tooth is damaged in a pinion having total 17 numbers of teeth, the peak is observed at each revolution as damaged tooth comes in mesh with the mating gear once in a revolution. But, in this case, the input shaft is rotating at $300 \mathrm{rpm}$ means the pinion is also rotating at a speed of $300 \mathrm{rpm}$. Converting this speed of pinion in revolutions per second $(\mathrm{Hz})$, a frequency of rotation of pinion is $5 \mathrm{~Hz}$. It means the pinion is completing 5 rotations in one seconds. This indicates that the pinion completes its one revolution in $(1 / 5)$ seconds i.e. in 0.2 seconds. It also denotes that the single damaged tooth will come in mesh with the mating gear once in 0.2 seconds. Due to the damage, the hike in amplitude of vibration acceleration at the meshing time is observed (Rusmir, et al, 2011).

From this we can say that the time waveform analysis is most compatible method of analysis to detect the teeth damage in gear.

In DEWEsoft X1 software, the manufacturers have provided the facility to convert the time waveform into Fast Fourier Transform (FFT) spectrum. By using that option some of the graphs of faulty pinion are converted into FFT power spectrum and those FFT spectrums are compared with that of the healthy pinion to identify the change in FFT. The comparison is made by using a tool provided in the Microsoft PowerPoint. The two FFT are overlapped on one another and one of them is made transparent. The FFT for comparison are shown in graph 2(a) and 2(b).

As the single teeth damaged pinion is compared with the healthy pinion, there is variation in number of teeth due to single damaged tooth. So, it is considered that, 16 numbers of teeth on faulty pinion and 17 numbers of teeth on healthy pinion. The peak is observed in FFT power spectrum at Gear Mesh Frequency.

$G M F=t \times N$

Where, $G M F=$ Gear Mesh Frequency,

$t=$ Number of teeth on gear,

$N=$ Speed in Hz. 
In all the three cases shown below, the peak observed for healthy pinion at its GMF is having higher value that the peak observed for faulty pinion at its GMF. This is due change in the number of teeth, ultimately due to change in GMF.

Sometimes it is difficult to identify the peak of GMF due more number of peaks in the FFT spectrum. If the load increases suddenly at a frequency near to GMF frequency due to various loads in a system, it is not possible to detect the peak of GMF.

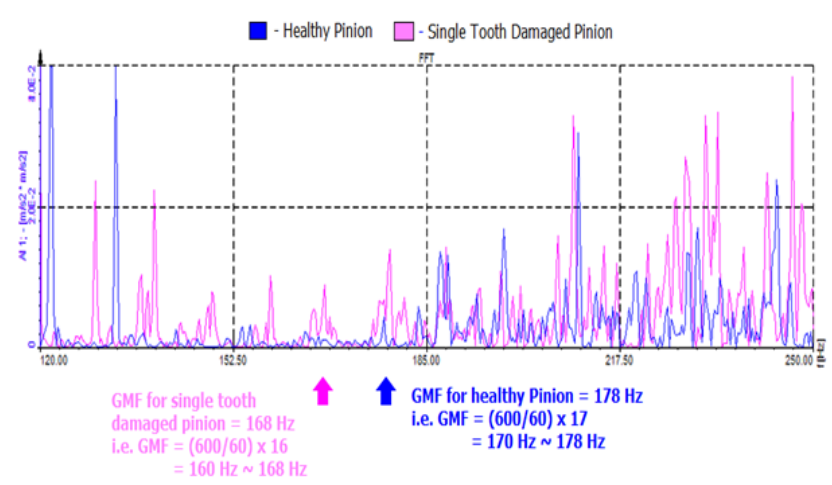

(a) At $600 \mathrm{rpm}$

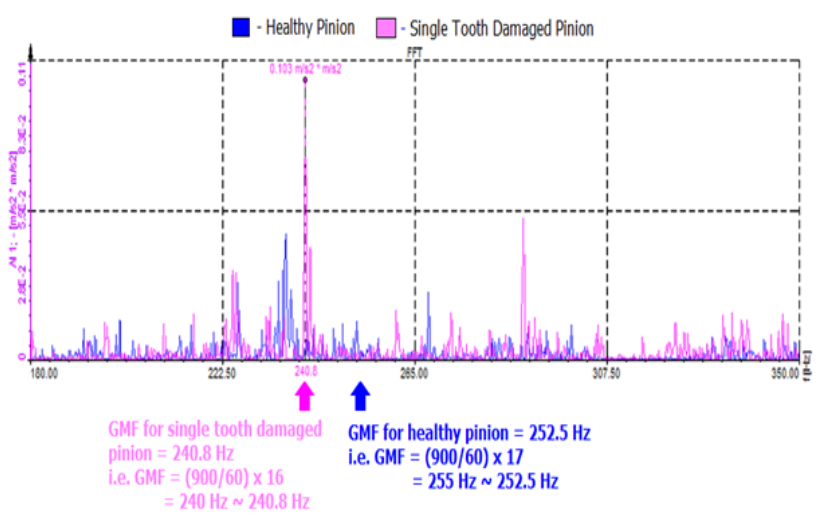

(b) At $900 \mathrm{rpm}$

\section{Graph 2 FFT power spectrums}

The values of GMF for both the gears in all the three cases are written in the figures. So it can be observed from this, the GMF for faulty pinion is at left side and for healthy pinion it is at right side which indicates that the GMF peak for healthy pinion is observed at higher frequency.

\subsection{Double Teeth Damage}

As the double tooth is damaged in a pinion having total 17 numbers of teeth, two peaks are observed at each revolution as damage comes in mesh two times in a revolution with the mating gear. But, in the experimental case, the input shaft is rotating at 300 rpm means the pinion is also rotating at a speed of 300 rpm. Converting this speed of pinion in revolutions per second $(\mathrm{Hz})$, frequency of rotation of pinion is $5 \mathrm{~Hz}$. It means the pinion will complete 5 rotations in one seconds. This indicates that the pinion completes its one revolution in $(1 / 5)$ seconds i.e. in 0.2 seconds. It also denotes that the two damaged tooth will come in mesh with the mating gear once in 0.2 seconds. It means the peak is observed after every 0.1 seconds as the two damaged teeth are exactly opposite to each other. Due to the damage, the hike in amplitude of vibration at the meshing time is observed. The same is shown in the graph 3 (Rusmir, et al, 2011).

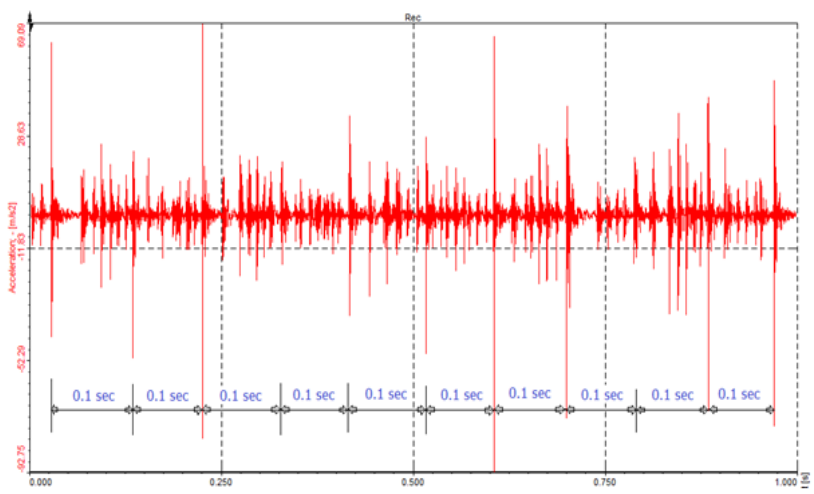

Graph 3 Time Waveform for Double Teeth Damaged Pinion at $300 \mathrm{rpm}$

So it becomes easier to detect the teeth damage in case of gears by using vibration analysis just by observing the time waveform.

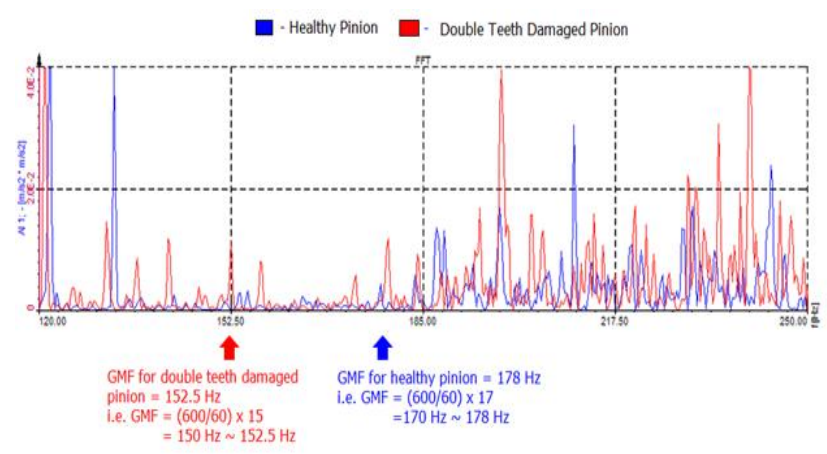

(a) At $600 \mathrm{rpm}$

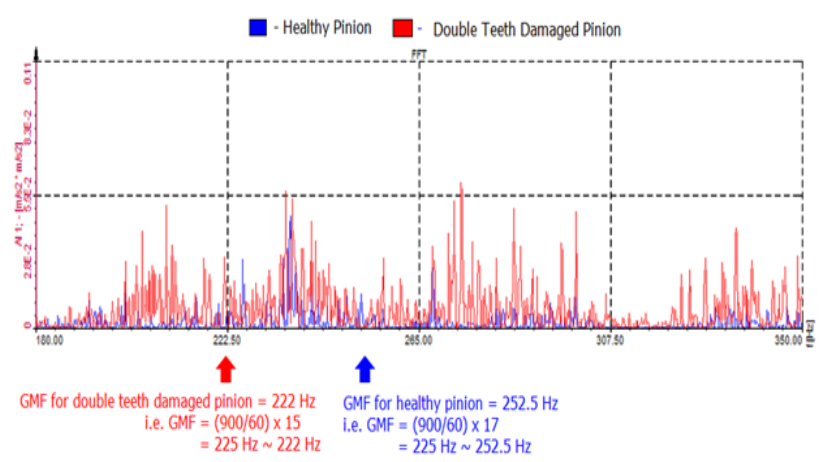

(b) At $900 \mathrm{rpm}$

Graph 4 FFT Power Spectrums 
As the double teeth damaged pinion is compared with the healthy pinion, there is variation in number of teeth due to two damaged teeth. So, it is considered that, 15 numbers of teeth on faulty pinion and 17 numbers of teeth on healthy pinion. The peak is observed in FFT at Gear Mesh Frequency.

In all the three cases shown below, the peak observed for healthy pinion at its GMF is having higher value than that of the peak observed for faulty pinion at its GMF. This is due change in the number of teeth, ultimately due to change in GMF.

In graph 4(a) and 4(b), the values of GMF for both the pinion are mentioned at their peak position. From this, it is observed that the GMF for the faulty pinion is at left side and GMF for the healthy pinion is at right side. It means that the peak at GMF for double teeth damaged pinion is observed at lower frequency than that of the peak at GMF for healthy pinion.

Due to different loading conditions, it may not be possible to identify precisely the peak observed due to GMF for faulty and healthy pinion. So, for identification of gear tooth fault, FFT spectrum will not be compatible. Rather than of observing at FFT spectrum, it will be easy to identify the tooth damage by using time waveform (L. Nacib, et al, 2013).

\subsection{Wear}

Raw data (time waveform) for healthy pinion and worn pinion are collected at various speed conditions. In the graph 5 , the comparative analysis of healthy and worn pinion is carried out by overlapping and making one of the time waveform transparent. The time waveforms for both the pinions are taken at a speed of $300 \mathrm{rpm}$ for 1 second.

The red colored time waveform is for worn pinion and blue colored waveform is for healthy pinion. It can be observed that the amplitude of acceleration is increased in case of worn pinion. Also the sub harmonics produced around sudden enlarged amplitude is increased. In case of more wear, the side bands are large and the amplitude is also large.

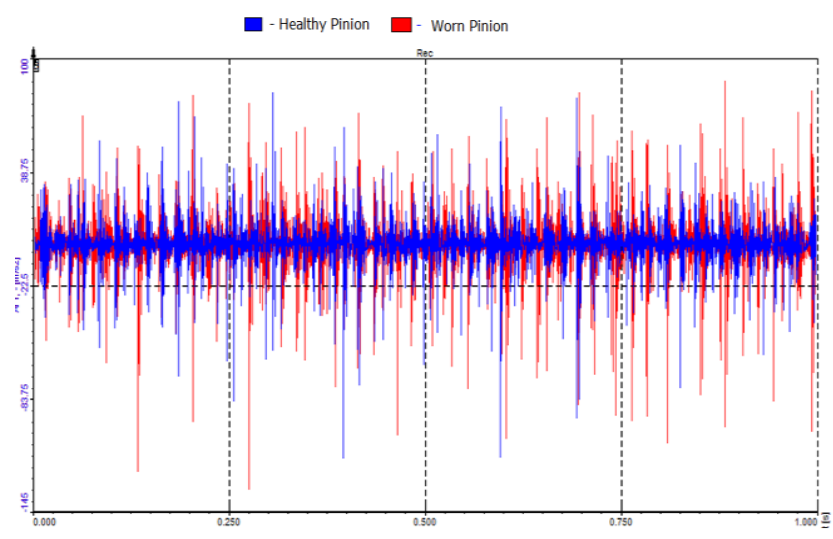

Graph 5 Time Waveform comparisons for healthy and worn pinion at $300 \mathrm{rpm}$
In graph 6, the root mean square comparison for healthy and worn pinion is shown. The blue colored line represents the worn pinion and the green colored line represents the healthy pinion. These all graphs are drawn at different speeds.

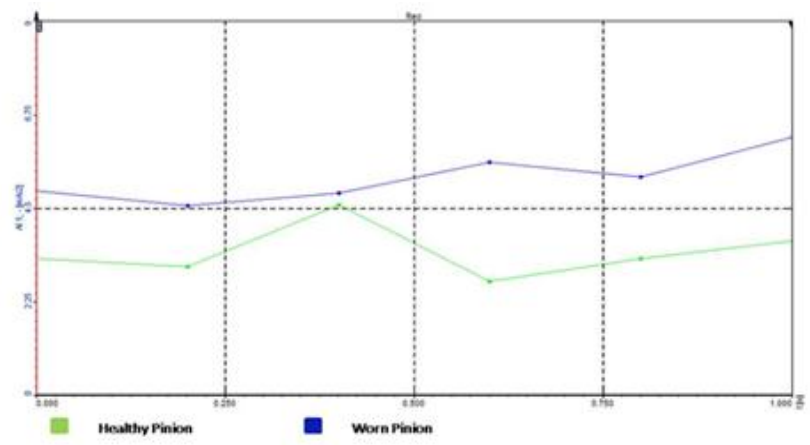

(a) At $300 \mathrm{rpm}$

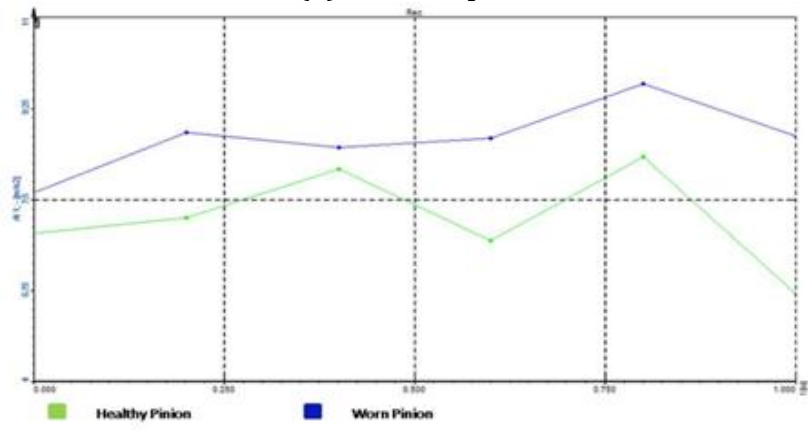

(b) At $600 \mathrm{rpm}$

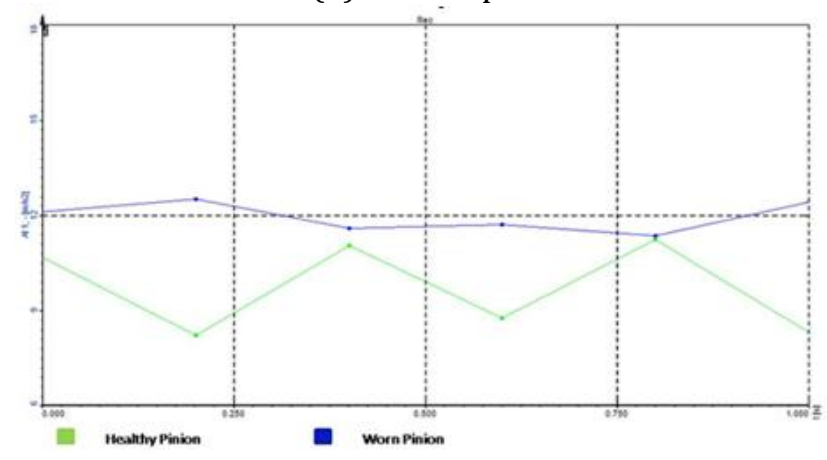

(c) At $900 \mathrm{rpm}$

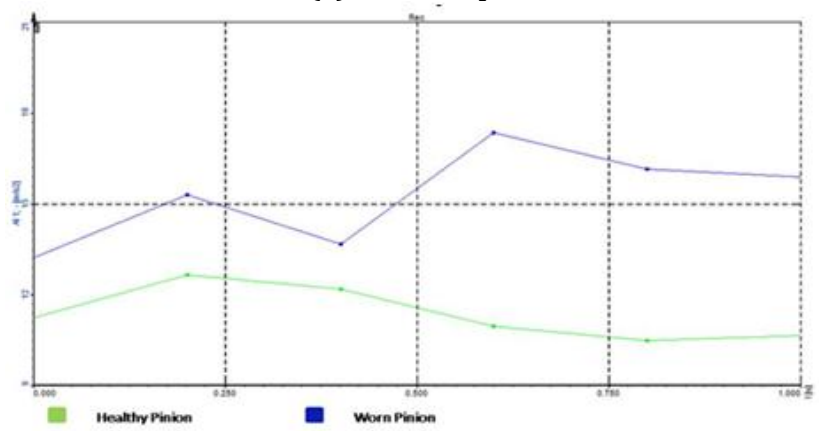

(d) At $1200 \mathrm{rpm}$

Graph 6 RMS value comparisons for healthy and worn pinion 
In each case it is observed that the RMS values for worn pinion is greater than the RMS value for healthy pinion. Also the variation in the RMS values for healthy and worn pinion is in small amount.

Table 2 RMS value and Variance comparison (RMS and variance are in $\mathrm{m} / \mathrm{s}^{2}$ )

\begin{tabular}{|c|c|c|c|c|c|}
\hline \multirow{2}{*}{ Pinion } & \multirow{2}{*}{$\begin{array}{c}\text { Speed } \\
\text { in rpm }\end{array}$} & \multicolumn{2}{|c|}{$\begin{array}{c}\text { Unloading } \\
\text { Condition }\end{array}$} & \multicolumn{2}{c|}{ Loading Condition } \\
\cline { 3 - 6 } & & RMS & Variance & RMS & Variance \\
\hline \multirow{2}{*}{$\begin{array}{c}\text { Health } \\
\text { y }\end{array}$} & $\mathbf{3 0 0}$ & 3.009 & 11.37 & 17.01 & 15.3 \\
\cline { 2 - 6 } & $\mathbf{6 0 0}$ & 7.859 & 99.98 & 23.42 & 39.41 \\
\cline { 2 - 6 } & $\mathbf{9 0 0}$ & 10.4 & 137.61 & 30.38 & 46.05 \\
\hline \multirow{3}{*}{ Worn } & $\mathbf{3 0 0}$ & 5.024 & 39.71 & 174 & 518.42 \\
\cline { 2 - 6 } & $\mathbf{6 0 0}$ & 8.379 & 87.88 & 726.4 & 1735.6 \\
\cline { 2 - 6 } & $\mathbf{9 0 0}$ & 11.65 & 157.33 & 996.7 & 2568.1 \\
\hline
\end{tabular}

From this table, it clears that in loading as well as in unloading conditions the RMS and variance values are greater in case of worn pinion (Kobra, et al, 2010).

So, from this part we can also say that by looking towards the time waveform and comparing the RMS values at different speed for healthy and worn pinion, it is possible to identify the fault like wear. But on the other part, it is difficult to identify the fault like wear, pitting, scoring and chipping by observing the FFT spectrum. It will become simple and reliable to identify by using some computational techniques like RMS and variance comparison.

\subsection{Fault Severity}

In graph 7, the RMS comparison is carried out for single tooth damaged pinion and double teeth damaged pinion. The red colored graph is used to represent the double teeth damaged pinion and the brown colored graph is used to represent the single tooth damaged pinion.

In this case, the RMS value for double teeth damaged pinion at all the conditions is greater than the RMS value for single tooth damaged pinion. This indicates that the increased damage indicates the increased RMS value.
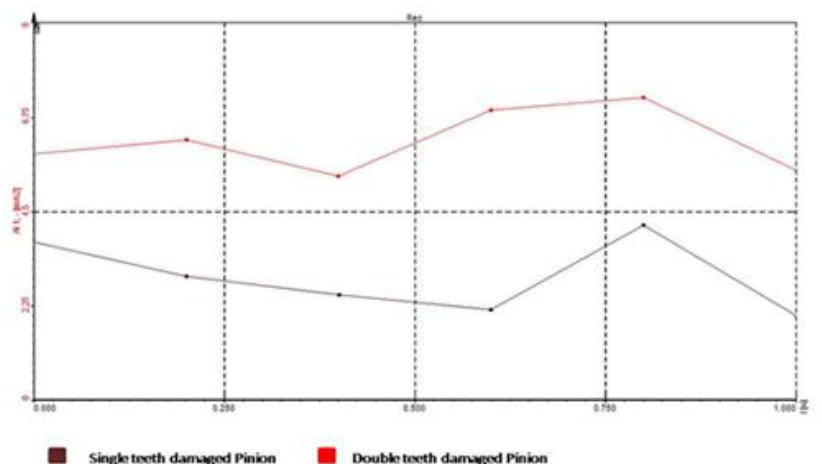

(a) At $300 \mathrm{rpm}$

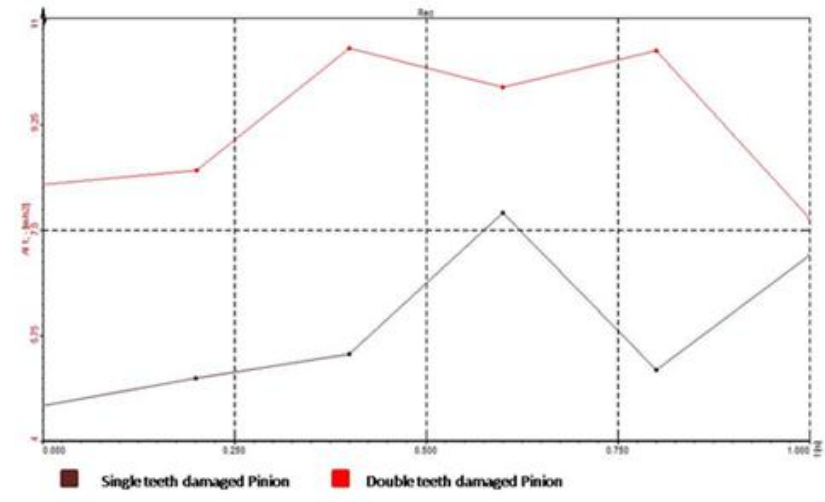

(b) At $600 \mathrm{rpm}$

Graph 7 RMS comparison for single and double teeth damaged pinion

The values of RMS and variance are given in the table 3 . The RMS value and the variance are greater in case of double teeth damage.

Table 3 RMS and Variance comparison for fault severity (in $\mathrm{m} / \mathrm{s}^{2}$ )

\begin{tabular}{|c|c|c|c|}
\hline \multirow{2}{*}{ Pinion } & $\begin{array}{c}\text { Speed in } \\
\text { rpm }\end{array}$ & RMS value & Variance \\
\hline \multirow{2}{*}{$\begin{array}{c}\text { Single } \\
\text { tooth } \\
\text { damage }\end{array}$} & $\mathbf{3 0 0}$ & 4.099 & 29.04 \\
\cline { 2 - 4 } & $\mathbf{6 0 0}$ & 4.502 & 23.82 \\
\cline { 2 - 4 } & $\mathbf{9 0 0}$ & 12.74 & 47.26 \\
\hline \multirow{2}{*}{$\begin{array}{c}\text { Double } \\
\text { Teeth }\end{array}$} & $\mathbf{3 0 0}$ & 14.71 & 174.02 \\
\cline { 2 - 4 } Damage & $\mathbf{6 0 0}$ & 6.683 & 41.15 \\
\cline { 2 - 4 } & $\mathbf{9 0 0}$ & 13.394 & 150.65 \\
\cline { 2 - 4 } & $\mathbf{1 2 0 0}$ & 19.7 & 383.38 \\
\hline
\end{tabular}

From these all figures shown above, it is observed that the severity of fault can also be found out by using proper vibration analysis. The RMS value and variance are the indicators of fault severity in vibration analysis (Kobra, et al, 2010).

\section{Conclusions}

After observing the graphs, tables and results, some of the conclusions have been drawn. These are discussed below according the fault conditions:

1) At $300 \mathrm{rpm}(5 \mathrm{~Hz})$ for single tooth damaged pinion, the damaged tooth comes in mesh with the mating gear once in each revolution. As the pinion is rotating at $5 \mathrm{~Hz}$ i.e. 5 revolutions per seconds, means one revolution of pinion is completed in $(1 / 5)$ seconds. As the damaged tooth comes in mesh, the large impact happens on the next tooth. Hence, the peak is observed after every 0.2 seconds.

2) At $300 \mathrm{rpm}(5 \mathrm{~Hz})$ for double teeth damaged pinion, the damaged teeth come in mesh with the mating gear twice in each revolution. As the pinion 
is rotating at $5 \mathrm{~Hz}$ i.e. 5 revolutions per seconds, means one revolution of pinion is completed in (1/5) seconds. As the damaged tooth comes in mesh, the large impact happens on the next tooth. Hence, the peak is observed twice after every 0.2 seconds. The same is shown in graph 3 , but the peak is shown at every 0.1 seconds.

From this observation, it can be concluded that the fault like single and double teeth damage can be identified just by observing the time waveform and speed.

3) From the values given in table 2 and graph 6, the magnitude of RMS value and variance is greater in case of worn pinion than the healthy pinion. It can be concluded that the fault like wear can be identified by using various computational techniques like RMS and variance.

4) In graph 7 and table 3, the RMS values and variance are compared for single tooth damaged pinion and double teeth damaged pinion. From these, it can be concluded that the magnitude of RMS value and variance for double teeth damage is greater. It also indicates that the computational techniques like RMS value and variance are applied to check the fault severity.

From this all, it can be concluded that the vibration analysis is the most suitable and easy technique to identify the fault conditions and fault severity. By observing the results it is possible to avoid complete breakdown of the rotating machinery without disassembling it. It is best suited method to identify the faults in any rotating machineries like gears, bearings, impeller unbalance and huge machineries like turbines, helicopter gearbox, wind turbine, industrial huge gear box etc. (Shawki, et al, 2012).

\section{Acknowledgement}

I feel happiness in forwarding this paper as an image of sincere efforts.
I am very much thankful to our respected guide Prof. G. D. Shrigandhi who has been a constant source of inspiration.I am also thankful to SKN Sinhgad College of Engineering, Korti and NBN Sinhgad College of Engineering, Solapur for providing FFT analyzer for experimentation and for guiding continuously. Also I am thankful to VVP Polytechnic, Solapur for providing facilities for manufacturing the experimental setup.

\section{References}

Aditendra Jaiswal, Dr. K. S. Zakiuddin, V. V. Shukla (2013), Fault Diagnosis of Gear by Vibration Analysis, International Journal of Latest Trends in Engineering and Technology (IJLTET), ISSN: 2278-621X, Vol. 3 Issue 1, Page No. 26-31.

C. Sujatha (2010), Vibration and Acoustics: Measurement and Signal Analysis, Tata McGraw Hill Education Private Limited.

G. Diwakar, Dr. M R S Satyanarayana, P. Ravi Kumar (2012), Detection of Gear fault using vibration analysis, International Journal of Emerging Technology and Advanced Engineering, ISSN: 2250-2459, Vol. 2, Issue 9, Page No. 123-136.

Kobra Heidarbeigi, Hojat Ahmadi, M. Omid (2010), Adaptive Vibration Condition Monitoring Techniques for Local Tooth Damage in Gearbox, Modern Applied Science, ISSN 1913-1844 E-ISSN 1913-1852, Vol. 4, Page No. 104-110.

Leila Nacib, Komi Midzodzi. Pekpr, Saadi Sakhara (2013), International Journal of Advances in Engineering \& Technology, ISSN: 2231-1963, Vol. 5, Issue 2, Page No. 139145.

Rusmir Bajric, Denijal Sprecic, Ninoslav Zuber (2011), Review of Vibration Signal Processing Techniques Towards Gear Pairs Damage Identification, International Journal of Engineering \& Technology (IJET - IJENS), Vol. 11 No. 4, Page No. 97-101.

Shawki Abouel-seoud, Ibrahim Ahmed, Mohamed Khalil (2012), An Experimental Study on the Diagnostic Capability of Vibration Analysis for Wind Turbine Planetary Gearbox, International Journal of Modern Engineering Research (IJMER), Vol. 2, Issue 3, Page No. 667. 675.

V. B. Bhandari (2010), Design of machine elements, McGrawHill Education India Pvt. Ltd. Third Edition. 